\title{
Institutional Advancement and Public Engagement in the STEM and Health Science Disciplines
}

Received (in revised form): June 14, 2007

\section{Victor A. Bloomfield}

is Associate Vice President for Public Engagement at the University of Minnesota in Minneapolis, Minnesota, and Professor in the Department of Biochemistry, Molecular Biology, and Biophysics, University of Minnesota-Twin Cities.

\section{Michelle Wittcoff Kuhl}

is the Program Associate in the Office for Public Engagement and doctoral candidate in the Department of Educational Policy and Administration, University of Minnesota, Minneapolis, Minnesota.

\begin{abstract}
In today's resource-scarce environment, science, technology, engineering, and mathematics (STEM) and health science disciplines must partner with institutional advancement offices to support two key components of research universities-research and graduate education. Framing the partnership in terms of societal needs helps advancement officers to attract resources to support important research and graduate education. Drawing on the collaborative process employed within STEM and health science colleges at the University of Minnesota, this paper outlines a framework for building and supporting new types of partnerships that
\end{abstract}

\footnotetext{
Author's Contact Address:

Victor A. Bloomfield

110 Morrill Hall

100 Church Street SE

Minneapolis MN, 55455, USA

Phone: +1 6126252268

Fax: +1612626 8388

Email: victor@umn.edu
}

benefit both society and universities' graduate research and education missions.

International Journal of Educational Advancement (2007) 7, 131-142. doi:10.1057/palgrave.ijea.2150054

Keywords:

STEM and health sciences, public engagement, institutional advancement

\section{Introduction}

Graduate education and research are key activities of research universities. The STEM disciplines (science, technology, engineering, and mathematics) and health sciences typically form a large proportion of the research and graduate education portfolios of research universities. In this paper we discuss how public engagement relates to STEM research and graduate education, and how partnerships with institutional 
advancement can be formed to support these relationships.

The Committee on Institutional Cooperation (CIC) Committee on Engagement in its draft 2005, Resource Guide and Recommendations for Defining and Benchmarking Engagement, defined engagement as "the partnership of university knowledge and resources with those of the public and private sectors to enrich scholarship, research, and creative activity; enhance curriculum, teaching and learning; prepare educated, engaged citizens; strengthen democratic values and civic responsibility; address critical societal issues; and contribute to the public good" (Committee on Institutional Cooperation, 2005).

This definition emphasizes the importance of reciprocal partnership in true engagement, in which both the university and the community partner bring their knowledge, expertise, and insight to bear on a problem. "Public engagement" is not just another term for "outreach." Rather, the partner's contribution might be comprehensive, including specific technical knowledge and problem definition in a universityindustry consortium, understanding of community cultural issues essential to a successful public health research project, or expertise in how to involve youngsters in a science museum exhibit of university research. Such contributions not only enhance the likely success of a project, but also ensure that the university's work will "address critical societal issues; and contribute to the public good."

The definition also emphasizes the relevance of engagement to the fundamental research and teaching missions of research universities, relevance which is being recognized inter alia by the $\mathrm{CIC}$, by a collective initiative of representatives of research universities and Campus Compact to renew the civic mission of higher education (Gibson, 2006), and by a 2005 Wingspread Conference on Graduate Education and Civic Engagement.

Underlying our discussion is the contention that scientific research, as it is currently carried out in this country, is generally engaged (even if its practitioners do not view it that way). The argument goes as follows: Most scientific research in universities is funded by federal agencies like the National Institutes of Health (NIH), the Department of Education (DOE), the Department of Defense (DOD), and the United States Department of Agriculture (USDA). They have goals in mind for the money they spend. Those goals are determined to a significant extent by public interest in research outcomes: treatments for cancer and other diseases, alternative energy sources, securing food and water supplies against terrorist threats, more efficient food production, etc. There is, therefore, a reciprocal partnership (a key piece of the definition of engagement) in which the "community" tells the university what its problems are, and chooses-through an advisory process-which ones it is willing to support. It is true that investigator-initiated research is a heavy part of the mix, but whether an investigator-initiated proposal gets funded depends on its congruence with agency priorities as much as on its intrinsic quality.

Even the National Science Foundation (NSF), the home of "pure research", now judges proposals on 
the criterion of broader societal impact as well as scientific quality.

In the biomedical arena, research is also funded by disease-oriented societies (American Cancer Society, Cystic Fibrosis Foundation, etc.). These organizations are even more involved in the choice of research priorities than are the federal agencies. Rare diseases often have patient advocacy groups that-though they may not provide much funding-are passionate in encouraging medical research, supporting national and worldwide databases, and participating actively in information networks.

Therefore, we contend that most of the scientific research carried out in universities fits the definition of engagement, so long as the definition of "community" is suitably broadened. Community should mean not just our home-town neighbors, but any group of people-possibly across the country or around the world-with whom we share interests and whose lives are entwined with ours in actively reciprocal ways. In the STEM and health science areas, this may include technology and biomedical companies, patient advocacy groups, foundations interested in human health and disease, and individuals and companies concerned with graduate education in these areas. All of these are potential targets of development efforts to supplement grant funds from federal agencies.

We begin our paper with a few case studies of engaged work from the STEM and health science disciplines that are examples of activities that funders and donors might find attractive. We proceed to reasons that the various participants in STEM research-faculty, graduate students, administrators, and society at large-might have for becoming more receptive to engaged approaches to working with institutional advancement officers. We conclude with some ideas about how advancement officials and university researchers might work together more effectively to develop cases for funding of engaged STEM and health science research and teaching.

\section{Examples of Engaged Research that Might Attract Funding}

These are examples drawn from recent activities at the University of Minnesota. We have chosen them because we know them best, but most research universities could give equivalent examples.

\section{STEM examples}

Engineers Without Borders (2006) is a "non-profit humanitarian organization established to partner with developing communities worldwide in order to improve their quality of life, and this partnership involves the implementation of sustainable engineering projects, while involving and training internationally responsible engineers and engineering students." Projects with which the University of Minnesota student chapter has been involved include improving the portability of the drinking water supply of the Grand Portage Band of Chippewa Indians, who obtain their water from Lake Superior, and developing a water sanitation system for a community-based boarding school in rural Thailand. 
A learning community project in the Department of Postsecondary Teaching and Learning in the College of Education and Human Development at the University of Minnesota integrated math, writing, and housing to study the effects of Hurricane Katrina on housing in New Orleans. Students gathered and analyzed statistics to correlate Katrina's damage to housing in various neighborhoods with ethnic and socio-economic factors, and wrote reports about their findings. They then participated in a Habitat for Humanity building in north Minneapolis, again using math to understand construction details. This project shows how many things can come together in publicly engaged teaching and learning: interdisciplinary approaches, new educational methods, and real-world applications.

The University of Minnesota's recently established Institute on the Environment (2006) articulates its goal as "Seeking Solutions to the Earth's Most Pressing Environmental Problems." It will assemble and support interdisciplinary teams to seek solutions to pressing environmental issues such as "global climate change, local, regional and global air pollution, loss of biological diversity, invasions by exotic plant and animal species, and contamination of groundwater, lakes, rivers and oceans" (Institute on the Environment, 2006).

\section{Health science examples}

Issues of access to healthy foods, proper nutrition, and child obesity in urban communities have emerged as crucial in the past few years. A public engagement symposium on Healthy Foods in Minneapolis Urban
Communities: Economic, Policy, and Community Strategies to Improve Healthy Food Access was held in March 2006 in Minneapolis. It brought together University researchers and community leaders to identify and discuss issues related to healthy food access in lower-income Minneapolis communities. Such issues are part of a larger concern about health disparities in populations of color, which suffer significantly higher mortality rates, teen pregnancy, heart disease, cancer, and diabetes, and markedly lower health insurance coverage. Faculty in the University of Minnesota School of Public Health are working to understand and remediate these problems.

The University of Minnesota Medical School has a program that places third-year medical students in rural practices, to work as a physician's apprentice. The program is becoming viewed nationally as a better way to educate doctors. Students gain continuous, integrated experience with a generational cross-section of patients, rather than seeing "cases" in a medical specialty context. They get front-line, hands-on experience, seem to learn at least as much as in the traditional curriculum, and do not develop the cynicism that now sometimes results. The rural physicians get some help, and the satisfaction of teaching. Society benefits in that more medical students may be attracted to rural practices, where the need is increasingly great; and in that the cost of medical care should be lowered by emphasizing preventive care to keep patients well rather than treating them when they are sick, and providing continuous care rather than sporadic contacts. 
The Consortium on Law and Values in Health, Environment \& the Life Sciences at the University of Minnesota puts on many interesting lectures and conferences on issues that connect academic studies on law and science with pressing public issues. To quote from their website: "Audiences include students and faculty from all departments on campus, legislators, attorneys, scientists, community members, and others. Each year most events are connected by a theme, most recently environment and biotechnology (2000-01); the revolution in genetic, reproductive, and stem cell technologies (2001-02); public health (2002-03); human subjects research, agricultural and environmental ethics, children's environmental health, and intellectual property rights (2003-04); medical devices and innovation, cutting-edge issues in stem cells, and the use of racial and ethic categories in biomedical research (2004-05); and implications of neuroscience, and the science, ethics and policy of energy and the environment (2005-06). In 200607 events will focus on nutrigenomics, nutraceuticals, and direct-to-consumer marketing of genomic nutritional profiling, and science and politicscontroversies in regulation and national security" (The Consortium on Law and Values in Health, Environment \& the Life Sciences, 2006). The Consortium has an associated Joint Degree Program in Law, Health \& the Life Sciences, which helps students combine a Law degree with a M.D., M.P.H., Ph.D. or M.S. in Molecular Biology \& Genomics, Environmental Studies, Medicine \& Health Policy, Science \& Technology Policy, or Drug Research \& Development.

\section{Interested groups}

We can identify at least three university groups with related but distinct interests in conducting research and graduate education in the STEM and health sciences in a way that may attract funding to support an engaged perspective: faculty, students, and administrators. Each of these groups has reasons to be skeptical of an engaged approach, but-we shall argue-stronger reasons to be supportive.

\section{Faculty}

Faculty in the STEM and health science disciplines are perhaps the most likely to be skeptical of the need-or even the desirability_of orienting their research to an engaged perspective, and of teaching their students this perspective. After all, these are the faculty who have access to the most plentiful sources of federal grant funds from NIH, NSF, DOE, DOD. They have done well with traditional approaches. Why do they need to make the effort to change? We think there are three main reasons.

First, as we have noted above, federal agencies-especially NSF and $\mathrm{NIH}$ - that provide the bulk of university research funding are requiring more attention to the social impacts and community involvement of proposed research. The NSF "broader impact criterion" requires applicants to spell out how their proposals will have an impact on society beyond the specific results of the research. This criterion is often proposed to be fulfilled by the training of students who will meet the needs of society for trained STEM workers. The case, however, is more convincing 
if the students come from underrepresented groups, or if there is a direct contact with K-12 or public education. For example, the University of Minnesota received a multi-million dollar NSF grant for research at its St. Anthony Falls Hydraulics Lab. A key factor in receiving the grant was the partnership of the university with the Science Museum of Minnesota, to develop a public education exhibit at the museum about groundwater hydrology. The NIH, when it funds community-based clinical research, is increasingly insisting that a diverse spectrum of community members be included in the study population. Without persistent and respectful community contacts, it will be difficult for researchers to satisfy this requirement.

Second, doing effective communitybased research is not trivial. Skills, attitudes, and personal contacts all need to be cultivated. Communities are often mistrustful of university researchers, who they think look on them as guinea pigs whom they can exploit for their own career objectives while bringing no benefit to the community (Grady, 1999; Thomas and Crouse, 1991). Whatever the general validity of this viewpoint, insensitivity on the part of some researchers has often poisoned the well for others. Communities are increasingly demanding to become full partners in research, helping to define the questions asked and the protocols used, expecting to be paid for their time, and learning the results of the study-couched in terms they find meaningful-in a timely fashion. They may wish to be co-investigators on the grant, or even principal investigators, obtaining a share of indirect as well as direct costs. There are also increasing calls for community-based institutional review boards (IRBs) on which community members are a majority rather than a token representation.

Third, STEM research and graduate education depends heavily on international students and collaborations. Students and postdocs from China, India, South Korea, and Taiwan make up a large fraction of the researchers in American university laboratories. They are particularly valuable because they often have better mathematical training than domestic graduate students. As these countries develop their own economies and educational and technical infrastructures, there may well be a decline in the numbers who seek training in the United States. At the same time, there may be a growth in international scientific and technical collaborations. Both of these eventualities point out the importance of faculty developing international contacts and domestic cultural sensitivities, which are validly viewed as aspects of engagement.

\section{Graduate and professional students}

Graduate students in the STEM disciplines and in the health sciences (including professional students in medicine, dentistry, public health, etc.) may have an even greater interest in engaged research and education than their faculty mentors. They will be the researchers and teachers of the next generation, and if-as we strongly believe-engagement with various publics is becoming increasingly important, their awareness and training will become essential career skills. 
Those graduate students who find positions in research-extensive universities will have much the same motivations to develop engagement skills and attitudes as their faculty mentors, as discussed in the previous section. Most graduate students will not, however, end up in Research I academic jobs. Many more of them will get jobs in industry, government, liberal arts colleges and community colleges. In those positions, ability to engage effectively with various community and public partners (both domestic and international) will be an essential part of their jobs.

A survey conducted as part of the Carnegie Initiative on the Doctorate asked more than 2000 graduate students in six disciplines what three things they would most like to see improved in their graduate experience. Learning more about the public issues addressed by the discipline ranked third out of 21 total response categories (see Carnegie Foundation for the Advancement of Teaching, 2007). Not surprisingly, how to formulate and carry out teaching and research programs were the top two. Many students recognize that there are important and interesting issues in the world to which their discipline could and should make a contribution, but only if it looks outward as well as inward. The results this research will appear in the forthcoming publication entitled, The Formation of Scholars: Graduate Education for the 21st Century (Walker et al., in press).

There are many opportunities for students to gain more engaged experience in their disciplines. If they are going to do engaged research, they will want to be sure that they get appropriate training in research methods courses or similar venues. (They should not take it for granted that their faculty advisors will do an adequate job.) Other opportunities include taking internships in science and engineering companies or in community clinics, visiting elementary or secondary schools to talk with students about interesting STEM topics and conduct demonstrations, tutoring younger students or acting as big brother/sister, participating in an organization such as Engineers without Borders, or acting as tour guide in a science museum.

\section{Administrators and their contacts in the broader society}

University administrators-presidents, chancellors, provosts, deans-are higher education's most direct points of contact with the broader society. They talk frequently with government officials and legislators, and serve on boards and committees with corporate and civic leaders. They are the spokespersons of the university's ambitions and aspirations, generally trying to make the case that what is good for the university is good for society. As President Robert $\mathrm{H}$. Bruininks, the University of Minnesota (2003), pointed out in his inaugural address, "Perhaps [our] greatest challenge-and the greatest opportunity-is to strengthen the connection between our research and education missions and the needs of our society."

One major issue that concerns both university administrators and leaders in the broader society is STEM "pipeline" issues. To make this issue concrete, consider the conference "Creating Minnesota's Plan for Career 
Development in Science, Technology, Engineering, and Math" that one of us (Bloomfield) attended in March 2006. The conference was arranged by the Citizens League, the Minnesota Department of Education, and the Science Museum of Minnesota. The conference participants included a wide range of leaders from business, education, government, and nonprofit organizations, and featured an address by the Governor of Minnesota.

The conference was motivated by these sobering challenges facing Minnesota:

- 20-33 percent projected increases in scientific and technical occupations in ten years;

- 10 percent decrease in the number of high school graduates by 2013 ;

- 52 percent increases in the number of graduate students of color, while Caucasian graduates decrease 18.7 percent;

- 20-40 point spreads between Caucasians and other cultural groups in science and math college readiness;

- 51 percent of superintendents report difficulty or great difficulty in filling science teaching positions;

- Only an average of 56.5 percent of newly hired teachers are still teaching after four years.

Three desired outcomes were listed for the conference:

- To come to a common understanding of these challenges Minnesota faces in meeting the STEM workforce needs of the future.

- To create a high-level shared vision to increase the number of STEM graduates across all cultural groups and income levels and to promote a higher level of STEM literacy for all graduates.

- To establish high-level priorities and strategies toward this vision involving business, education, government, and nonprofit organizations within communities and across the state of Minnesota.

Clearly, networks of engaged partnerships among higher education, schools, government, business, and civic organizations are needed to cope with these challenges; and top university administrators view them as high priorities. Efforts are likely to be more successful if they are carried out as engaged partnerships rather than as traditional one-way outreach.

Another area where STEM, administrative, and broader societal issues intersect is international students, workers, and collaborations. A substantial proportion of our STEM students-both undergraduate and graduate-and workers are international, and maintaining a steady flow of talent to the United States is a high priority of both research universities and high-tech businesses. International collaborations in health, agriculture, and many STEM fields are also growing in importance to the plans of research universities.

\section{Working with Advancement Officers}

\section{Colleges and departments}

The STEM disciplines are relatively well supported by federal grants. So one may ask why special advancement efforts are needed. The answer is that 
most grants from NIH, NSF, DOE, DOD, etc. include funding only for the conduct of the research itself. Generally the institution is expected to cover the costs of public engagement from other sources. Most importantly, the costs of recruitment, counseling, and outreach needed to build a student pipeline from K-12 to university are rarely covered, nor are the costs of public education or outreach activities. These costs would seem to be prime targets for engagement-targeted institutional advancement, since they directly address community as well as university needs.

While advancement officers maintain connections with the central university foundation, it is through interactions within their college that they have the best opportunities for partnership with faculty and graduate students in the STEM disciplines. In order to understand how to build the partnerships between advancement officers and faculty and graduate students in the STEM disciplines, we consulted with advancement officers in three science and engineering colleges at the University of Minnesota: the College of Biological Sciences, the Institute of Technology, and the College for Agricultural, Food, and Environmental Sciences. We learned six primary lessons from our conversations with these development professionals.

First, the most successful collegiate advancement officers have good contacts with all groups in the college. Positive relationships must exist between the advancement office, the administrative leadership, and key faculty and students in the college, because advancement has become a team activity.
Second, advancement has evolved, and it is not simply about asking people for their money. The perception among some faculty, staff, and students is that advancement officers simply find wealthy people and try to convince them to give money to the college or university they are representing. This perception is inaccurate. In fact, advancement is a much more engaged process whereby the advancement officer listens to the wishes of the prospect and tries to match their interests and values with initiatives and research going on in the college. It is essential that faculty and students are part of this matching process, because they can inform the advancement officers of what new and exciting things are going on in the college and how they might connect to public engagement concerns.

Third, just as the best public engagement is a true two-way partnership, the advancement officers noted that a real partnership has to exist for collegiate advancement to be maximized. The first step is to develop knowledge about the different units within the college. Advancement officers in our STEM colleges all emphasized they needed good working relationships with their department chairs or heads. When a new chief advancement officer came on board, he or she quickly had to go out to the departments and become educated about their work.

Fourth, the advancement officers noted that department chairs, faculty, and graduate students needed to learn how to articulate their research and interests within a broader societal context. In other words, the advancement team and the academic team needed to be able to translate the 
research going on into terms that could be understood by a multitude of stakeholders and be valued by a diverse audience. As Shelly Strickland points out in this special issue of the International Journal of Educational Advancement, transformational giving has its roots in making broad societal change, and the engaged work of the STEM disciplines and graduate schools are poised to work on global critical issues.

Fifth, many of the officers gave presentations to the faculty and staff within the colleges to help them understand the process they use in developing prospects and working with them to try to find a match for their interests within the college. This information not only helps to remove the mystery of advancement, but also builds interest in developing a cooperative relationship.

Sixth, advancement offices need strong relationships with the college administration. Understanding the needs and priorities of the dean of the college, and how that dean can be a positive force in advancement work, is imperative. The dean is the face of the college in many public arenas and interacts with prospective donors on a regular basis. Access to the dean of the college can significantly improve the likelihood of a development team reaching institutional goals.

\section{Working with the graduate school}

Although doing advancement work to raise resources for public engagement activities within STEM departments and colleges may not be terribly different from other sorts of college- based advancement, trying to raise funds for engaged graduate research and education within a graduate school context can be quite different. Most graduate schools are entities within central administration, which may put them in competition with collegiate fundraising since graduate students and alumni owe allegiance both to their home departments and the graduate school. Perhaps for this reason, many graduate schools do not have advancement offices, or have established them only recently.

If graduate schools are purely administrative entities, concerned solely with admissions and satisfaction of degree requirements, they may have no need for development activities. Graduate schools are, however, increasingly establishing programs that supplement the purely disciplinary offerings of departments. Some examples are Preparing Future Faculty, providing training on research ethics and the public implications of scholarship, and providing fellowship support for students from underrepresented groups or for research projects with an engagement or community outreach focus. In addition, the graduate school is often the home of interdisciplinary research projects or centers, and is called upon to provide resources to support these enterprises, which often have a public engagement focus.

All of these graduate school activities require substantial resources, which may not be readily available through internal university channels. This is an area in which advancement efforts devoted to the graduate school itself may be necessary and valuable. 


\section{Broader institutional issues}

Since the graduate school is typically a bridge between departments and central administration, it is a good example of a situation in which a relationship between advancement officers and administrative units is beneficial for broad institutional priorities. In many cases, larger institutional initiatives can build relationships between advancement officers and STEM research and graduate education. For example, when the Office for Public Engagement at the University of Minnesota was assembling ideas about how to start collecting system-wide engagement information, it went to a meeting of all the advancement officers across the system. They served as a focus group and provided important feedback about how this project might be useful to their work, both institutionally and in the colleges.

More generally, the foundation and its staff have to be engaged by offices and departments in the strategic planning process about how to move forward as an institution. We, however, identify three main difficulties involved in this process.

First, building these relationships takes time. A culture change within the college may be necessary. Relations between the advancement team and faculty and students may or may not have been positive in the past, or a significant advancement effort may be a new priority for a college.

Second, there may be conflicts between undergraduate and postgraduate fundraising priorities. Many graduates of STEM colleges pursue further study in professional or graduate schools. The college has to develop an alumni base that connects with their undergraduate institution as well as with their graduate or professional school alma maters.

Third, it can be difficult for advancement officers to navigate approaches to some prospective donors. A large charitable foundation or very wealthy potential donor may be the target of many prospective approaches, and competition within the institution for asking rights can be intense. The competition may be heightened if a project crosses college lines, so that intercollegiate or interdisciplinary proposals (many public engagement projects fall into this category) must contend with the clearer priorities within a single college.

Nevertheless, such institutional complexities may be opportunities in disguise. As a wise person has observed, "Universities have departments, while society has problems." As Strickland's research in this issue suggests, many potential donors are more interested in solving important societal problems than in supporting parochial departmental interests. Institutional advancement efforts that support the interests of donors in helping to address societal problems by engaged research and teaching may have a good chance of success, even if they require somewhat unorthodox approaches and alliances within the institution. In the end, we believe that the potential payoff to society, and to the institution, make the chance well worth taking.

\section{References}

Bruininks, R.H. (2003), Advancing Knowledge: A Partner for the Public Good Inangural Address, available online: http://www1.umn.edu/pres/ inaug/address.html. 
Carnegie Foundation for the Advancement of Teaching (2007), Carnegie Initiative on the Doctorate, available online: http://www.carnegiefoundation. org/programs/index.asp?key=29.

Committee on Institutional Cooperation (2005), Committee on Engagement, available online: http://www.cic.uiuc.edu/groups/ CommitteeOnEngagement/index.shtml.

Consortium on Law and Values in Health, Environment \& the Life Sciences (2006), available online: http://www.lifesci.consortium. umn.edu/conferences.

Engineers without Borders (2006), available online: http://www.ewb-usa.org/.

Gibson, C. (2006), "New times demand new scholarship: Research universities and civic engagement", Campus Compact, available online: http://www.compact.org/resources/ research_universities.
Grady, D. (1999), "Patient or guinea pig," The New York Times, January 5, Health Section.

Institute on the Environment (2006), available online: http://www.academic.umn.edu/provost/ interdisc/environment/IoEfinalreport.pdf (September 25, 2006).

Thomas, S.B. and Crouse Quinn, S. (1991), "The Tuskegee Syphilis Study, 1932 to 1972: Implications for HIV education and AIDS risk education programs in the black community," American Journal of Public Health, 81, 11, pp. 1498-1506.

Walker, G., Golde, C., Bueschel, A., Jones, L. and Hutchings, P. (in press), The Formation of Scholars: Graduate Education for the 21st Century, Carnegie Foundation for the Advancement of Teaching, Palo Alto, CA. 